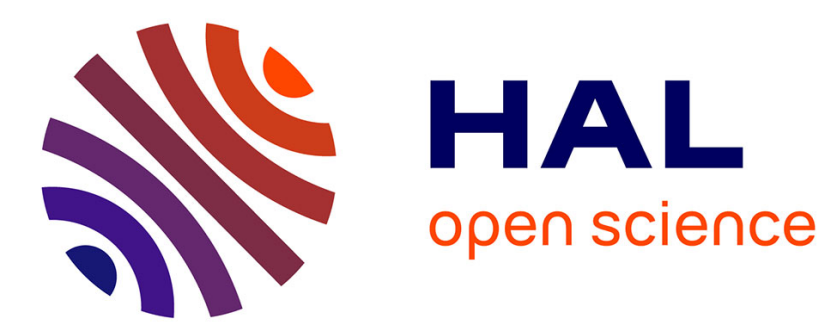

\title{
Azathioprine for refractory ulcerative proctitis: A retrospective multicenter study
}

Anne-Laure Mallet, Guillaume Bouguen, Guillaume Conroy, Xavier Roblin, Jean-Bernard Delobel, Jean-François Bretagne, Laurent Siproudhis, Laurent Peyrin-Biroulet

\section{To cite this version:}

Anne-Laure Mallet, Guillaume Bouguen, Guillaume Conroy, Xavier Roblin, Jean-Bernard Delobel, et al.. Azathioprine for refractory ulcerative proctitis: A retrospective multicenter study. Digestive and Liver Disease, 2017, 49 (3), pp.280-285. 10.1016/j.dld.2016.12.001 . hal-01483854

\section{HAL Id: hal-01483854 \\ https://hal-univ-rennes1.archives-ouvertes.fr/hal-01483854}

Submitted on 22 May 2017

HAL is a multi-disciplinary open access archive for the deposit and dissemination of scientific research documents, whether they are published or not. The documents may come from teaching and research institutions in France or abroad, or from public or private research centers.
L'archive ouverte pluridisciplinaire HAL, est destinée au dépôt et à la diffusion de documents scientifiques de niveau recherche, publiés ou non, émanant des établissements d'enseignement et de recherche français ou étrangers, des laboratoires publics ou privés. 


\section{AZATHIOPRINE FOR REFRACTORY ULCERATIVE PROCTITIS: A RETROSPECTIVE MULTICENTER STUDY}

Short title: azathioprine for refractory ulcerative proctitis

\section{Authors}

Anne-Laure Mallet ${ }^{1}, \mathrm{MD}$, Guillaume Bouguen ${ }^{1,2,3}, \mathrm{MD}, \mathrm{PhD}$, Guillaume Conroy ${ }^{4}, \mathrm{MD}$, Xavier Roblin ${ }^{5}$, $\mathrm{MD}, \mathrm{PhD}$, Jean-Bernard Delobel ${ }^{1}$,MD, Jean-François Bretagne ${ }^{1}, \mathrm{MD}, \mathrm{PhD}$, Laurent Siproudhis ${ }^{1,2,3}, \mathrm{MD}$, $\mathrm{PhD}$ Laurent Peyrin-Biroulet ${ }^{4}$ MD, PhD.

${ }^{1}$ Department of Hepato-Gastroenterology, University Hospital of Pontchaillou, Rennes, France;

${ }^{2}$ Inserm 991, University of Rennes 1, France;

${ }^{3}$ CIC1414, Université de Rennes 1, France;

${ }^{4}$ Department of Gastroenterology, Inserm U954, Nancy University Hospital, Lorraine University, France; ${ }^{5}$ Service de Gastrologie-Entérologie-Hépatologie, CHU de Saint-Etienne, Saint-Etienne, France5, Inserm U954 and Department of Hepato-Gastroenterology, France.

\section{Correspondence to:}

Guillaume Bouguen

Service des Maladies de l'Appareil Digestif

2 rue Henri le Guillou

35033 Rennes cedex, FRANCE

Telephone (0033)-2-99-28-43-17 / Fax (0033)-2-99-28-41-89

Email: guillaume.bouguen@free.fr

\section{ABSTRACT}

Background: Efficacy of azathioprine (AZA) in refractory ulcerative proctitis (UP) is unknown.

Methods: All patients treated with AZA for refractory UP in three referral centers between 2002 and 2012 were included. "Treatment success" in the long-term was defined as the absence of colectomy during follow-up, no need for anti-TNF during follow-up, no ongoing systemic steroids use, no adverse event leading to AZA withdrawal, and clinically quiescent disease at last follow-up.

Results: Of the 1279 adult patients with ulcerative colitis, 25 patients were treated with AZA for refractory UP (median disease duration 4.9 years). Of these, 4 had no short-term clinical assessment. Of the remaining 21, 4 were primary non responders to AZA, 7 discontinued AZA for adverse events and 10 showed clinical improvement. At the long-term assessment at last follow up after a median of 46 months, 
5 patients had treatment success and were still on AZA treatment, the remaining 20 were treatment failures. Of these, 5 discontinued AZA for adverse events and 15 were treated with infliximab (clinical response in 11 patients, primary non-response in one patient, and 3 underwent colectomy).

Conclusion: AZA may be efficacious in maintaining clinical response in one-fifth of patients with refractory UP in a real-life setting.

Keywords: proctitis, ulcerative colitis, azathioprine

\section{INTRODUCTION}

Ulcerative proctitis (UP) represents the benign end of the spectrum of ulcerative colitis (UC) confined to the rectum that may result in distressing symptoms including increased stool frequency, tenesmus, urgency and bleeding ${ }^{1}$. The incidence rate for UC varies from 0.5 to 24.5 per 100,000 person-years with $22 \%$ to $60 \%$ of patients with UP at diagnosis ${ }^{2-5}$. The cumulative rate of relapse after the diagnosis of UP was $42 \%, 57 \%$ and $84 \%$ at 2-yr, 5-yr and $10-\mathrm{yr}$, respectively ${ }^{6,7}$. Nearly $22 \%$ of patients with UP had disease progression within 12 to 24 months of initial diagnosis ${ }^{8}, 28 \%$ within the first five years of followup ${ }^{9}$, and up to $38 \%$ at 10 years ${ }^{1}$. Importantly, patients with UP showing an aggressive disease course with relapsing disease and refractory to conventional treatment are more prone to show proximal extension and ultimately to undergo surgery ${ }^{1}$. A recent population-based cohort on the outcome of pediatric-onset UP showed that half of the children had proximal extension at 10 years with a $10 \%$ risk of colectomy at 5 years. $^{2}$

Despite the significant benefits of rectally administered aminosalicylates (ASA) and corticosteroids, some patients with UP fail to improve and require additional medical therapy ${ }^{10}$. The management of patients with refractory UP remains challenging due to the low level of evidence for available drugs. ${ }^{10}$ Several medications have been tested, but study results remain difficult to interpret due to small sample size and the exclusion of UP from randomized controlled trials. In a recent study, infliximab (IFX) showed encouraging results in a small population of refractory UP with $85 \%$ of clinical response after the induction therapy that was maintained for $82 \%$ of patients after a median follow-up of 17 months ${ }^{11}$. Rectal tacrolimus ointment for refractory UP has been assessed in small open-label studies and seems to be safe and effective ${ }^{12-14}$. Intramuscular methotrexate and oral tacrolimus showed some efficacy to induce and maintain clinical response in UC, but data for UP are also scarce ${ }^{15,16}$. In randomized 
controlled trials, antibiotics ${ }^{17,18}$, cyclosporine enemas ${ }^{19}$ were not associated with long-term clinical response and remission. Other miscellaneous medications were tested without clear evidence for their use such as probiotic therapy, herbal preparations, nicotine, heparin, short-chain fatty acid, lidocaïne or probiotics. $^{20-24}$

Purine analogs -azathioprine (AZA) and 6-mercaptopurine (6-MP)- may be effective in UC patients ${ }^{25}$. Interestingly, Love and colleagues reported complete or moderate improvement in the short term in $63 \%$ of 27 patients with intractable proctosigmoiditis treated with 6-MP, but lesions could be observed up to $50 \mathrm{~cm}$ from the anal verge ${ }^{26}$. Overall, the effectiveness of thiopurine in treating refractory UP remains poorly known.

The aim of this study was therefore to assess the short and long-term term outcome of refractory UP treated with AZA in a retrospective multicenter study.

\section{METHODS}

\section{Study population}

All hospital records of adult patients (age $>18 \mathrm{yr}$ ) with UC $(\mathrm{n}=1279)$ in 3 French tertiary referral centers (University Hospitals of Rennes, Nancy, Saint-Etienne) between June 2002 and January 2012 were reviewed. Diagnosis of UC was based on clinical, radiological, endoscopic and/or histological evidence. UP was defined according to the Montreal classification : "involvement limited to the rectum (that is, proximal extent of inflammation is distal to the rectosigmoid junction)"27. All adult patients treated with AZA for documented refractory UP to standard medications were included. Refractory UP was defined by the absence of response to either local administration of 5-ASA or steroids.

The following demographic and clinical data were collected at the date of enrolment: age, sex, weight, date of diagnosis, phenotype disease (Montreal's index), medical and surgical past history, date of AZA initiation, previous and concomitant treatment.

\section{Follow-up}


"Short-term" outcome was judged according to clinical, biological and endoscopic reports mentioning the evolution of refractory UP between 3 and 9 months after AZA initiation and "long-term" outcome according to data at last follow-up. AZA maximal daily dose and all therapeutic changes during follow-up were recorded. Date and reason of AZA discontinuation were recorded.

The presence of symptoms including number of stool per day, rectal bleeding, rectal disorders were recorded at AZA initiation and during the follow-up. Rectal disorders were considered as present when patient suffered from at least stool urgency, incontinence, tenesmus or rectal pain. According to physician clinical assessment, the disease activity at baseline was classed as mild, moderate or severe. Both shortand long-term clinical response were defined according to the physician global assessment as complete (clinical remission) in the absence of diarrhea, rectal bleeding and rectal disorders, partial if there was a marked clinical improvement but still persistent mild symptoms and no response in other cases. ${ }^{5}$ Endoscopic disease activity was defined according to the Mayo's endoscopic sub-score: (0) normal, (1) mild disease with erythema, decreased vascular pattern, friability erosion and lack of spontaneous bleeding, (2) moderate disease with marked erythema, absent vascular pattern, friability and erosion, (3) severe with ulceration and spontaneous bleeding. ${ }^{28}$ Endoscopic remission at short and long-term was defined by Mayo endoscopic subscore of $0-1 .{ }^{28}$ Partial response was defined by a decrease of the Mayo endoscopic subscore from 3 to 2, and no response in other cases. all endoscopic reports performed during the follow-up were collected and mucosal healing was considered when it was observed at least once during the follow-up.

"AZA treatment success" was defined by the absence of colectomy during follow-up, no need for antiTNF during follow-up, inactive disease at last follow-up, no ongoing systemic steroids at last follow-up and no AZA withdrawal due to adverse event. The other patients were considered as "treatment failure". All adverse events occurring during or after AZA beginning and until last follow-up were collected.

\section{Statistical analysis}

Due to the small sample size, statistical analysis was limited to descriptive statistics. Quantitative variables were described as median \pm inter-quartile range [25-75\%] and categorical variables were presented as counts and percent of the cohort. 


\section{RESULTS}

\section{Baseline characteristics of the patients}

A total of 1279 patients with UC were screened in the 3 referral centers and 25 patients were included (sex ratio M/F: 11/14). The baseline characteristics at AZA initiation are depicted in Table 1 . The median age of population was 34.7 [27.1-47.9] years and median duration of UP at AZA initiation was 4.9 [2.08.9] years. Almost all patients received prior oral or rectal 5-ASA (24 (96\%) and 23 (92\%) patients, respectively). Eighteen patients (72\%) were previously treated with rectal steroids and $21(84 \%)$ with systemic steroids. One patient (4\%) had prior exposure to cyclosporine. None had prior intestinal surgery. All patients presented an active UP with rectal disorders $(n=17)$ and/or bloody stools $(n=20)$ at AZA initiation. The disease activity was judged by the physician as mild in $2(8.0 \%)$ patients, moderate in 17 $(68.0 \%)$, and severe in $6(24.0 \%)$ patients.

Among the 18 patients who had baseline endoscopy, one patient (5.6\%) had an endoscopic Mayo score of 1, $12(66.7 \%)$ Mayo 2 and $5(27.8 \%)$ Mayo 3.

\section{Azathioprine and concomitant medications at baseline}

Concomitant medications at AZA initiation are summarized in Table 1. AZA was prescribed for refractory UP with 5-ASA in $14(56 \%)$ patients (oral, topical or both in 5 and 2 and 7 patients, respectively). Systemic or topical corticosteroids were combined with AZA in 21 (84\%) patients. A combination of 5-ASA, steroids and AZA was used in 11 (44.0\%) patients. None of the included patients received IFX at AZA initiation.

\section{Short-term outcome (Figure 1)}

Of the 25 patients, 4 patients had missing data with no documented clinical visit during the first 9 months of AZA treatment. Hence 21 patients could be analyzed for short-term outcome (3-9 months after AZA treatment initiation) after a median time of 5.5 [3.9-7.4] months. Seven patients stopped AZA due to adverse events during the first 3 months of AZA treatment. Therefore 14 patients could be analyzed for short-term efficacy. Four out of 14 patients were primary non-responders; all 4 primary non-responders 
received concomitant rectal steroids and 3 systemic steroids (75\%) at the time of AZA initiation. None received IFX therapy during this induction period. Ten out of 14 patients were primary responders. Three out of the 10 primary responders were in steroid-free clinical remission and 7 patients had a partial clinical response. The 10 primary responders received at the time of AZA initiation concomitant rectal steroids $(n=5)$, systemic steroids $(n=6)$, rectal 5-ASA $(n=4)$ and/or oral 5-ASA $(n=3)$.

Endoscopy was performed in 4 patients during this induction period: 2 were primary non-responders and 2 had partial response; none of them had mucosal healing. None of the 10 primary responders had endoscopic assessment during the induction period.

\section{Long-term outcome (Figure 1)}

Data on the long-term outcome were available for all included patients $(n=25)$. Median duration of AZA treatment was 9 [2.0-32.8] months. The median maximal AZA dose was 150 [118-162] mg/day, equivalent to $2.2[2.0-2.5] \mathrm{mg} / \mathrm{kg} / \mathrm{day}$.

After a median follow-up of 46.2 [26.4-47.8] months, 5 patients had treatment success at last follow-up (absence of colectomy during follow-up, no need for anti-TNF during follow-up, inactive disease at last follow-up, no ongoing systemic steroids at last follow-up and no AZA withdrawal due to adverse event). All 5 patients were still treated with AZA at last follow-up.

Among the 20 patients considered as treatment failure, IFX treatment was introduced in 15 patients (IFX was used in monotherapy for 10 patients and in combination therapy with AZA for 3 patients or with methotrexate for 2 patients) leading to steroid-free clinical remission in 9 patients, while 2 patients experienced significant clinical improvement from baseline, 3 underwent colectomy, and one patient was primary non-responder with still clinically active disease at last follow-up. The 5 remaining patients who did not receive anti-TNF therapy during follow-up had stopped AZA treatment due to adverse event and were thus considered as treatment failure: 2 patients were in clinical remission on oral 5-ASA alone $(\mathrm{n}=1)$ or in association with topical 5-ASA $(n=1)$ at last follow-up, and 3 still had clinically active disease at last follow-up (2 without medical treatment and one on oral 5-ASA).

Endoscopy was performed after the induction AZA treatment period in 20 of the 25 included patients. Eighteen out of 20 patients had mucosal healing (endoscopic Mayo score of 0 or 1 ). The two patients 
without mucosal healing started IFX treatment. Among the 18 patients with mucosal healing, 4 patients had treatment success (one patient of the treatment success group $(n=5)$ did not have endoscopic evaluation), 10 patients started IFX treatment, and 4 patients stopped AZA treatment due to adverse event.

Of note, 4 patients presented a proximal extension to a left-sided colitis at endoscopy performed after the induction period: one underwent colectomy following IFX failure, 2 patients were successfully treated with IFX, and one had treatment success on AZA at last follow-up.

\section{Safety}

Seven adverse events were reported in 7 patients. All adverse events occurred within the first 3 months of treatment and led to drug withdrawal: 3 gastrointestinal intolerance, 3 allergic immune reactions, and one case of cytolytic hepatitis. No opportunistic infection, no tuberculosis, no pancreatitis, no malignancy were observed during follow-up.

\section{DISCUSSION}

The present study assessed for the first time the outcomes of patients treated with AZA for refractory UP. Proctitis is a frequent disease location affecting $22 \%$ to $60 \%$ of UC patients at diagnosis and a disabling condition significantly altering quality of life ${ }^{2-5}$. UP is usually considered as mild by physicians who usually delay the need for immunosuppressant or biologics even in case of refractory UP as there is no fear of colorectal cancer. ${ }^{29}$. Accordingly, only $2 \%$ of UC patients treated in 3 French referral centers were treated with AZA for UP.

The disabling course of UP is also related to the risk of disease extension in these patients. One-fifth of ulcerative patients included in the IBSEN cohort with proctitis or left-sided colitis had progressed to extensive colitis ${ }^{5}$. Refractory UP is a known risk factor for disease extension ${ }^{1,30}$. Consistently, we found that $20 \%$ (4/20) of patients had disease extension at last endoscopy. This information is reliable as 20 out of 25 patients had endoscopic assessment after the AZA treatment induction period, even though 15 patients were treated with IFX therapy, which may prevent disease progression. 
A total of $40 \%$ of patients had short-term clinical response after AZA initiation and one fifth of patients were in sustained clinical benefit at last follow-up after a median follow-up of 4 years. In the SUCCESS trial, patients treated with AZA for UC achieved corticosteroid-free remission in $23.7 \%$ of cases at week $16^{31}$, which is in line with long-term results of the present study. As in all UC controlled trials on biologics, patients with UP were excluded from the SUCCESS trial ${ }^{31}$. The rate of mucosal healing was $36 \%$ at week 16 in the SUCCESS trial in thiopurine-treated patients ${ }^{31}$. Interestingly, only primary nonresponders to AZA had endoscopic evaluation during the induction period in our study. This reflects clinical practice during the study period when therapeutic decision was based only on symptoms in IBD patients, whereas clinical and endoscopic remission was recommended in recent international guidelines 28,32 .

Few previous studies reported the long-term outcomes of AZA among UC patients and showed high rates of corticosteroid-free remission ranging from $45 \%$ to $55 \%$ after a maximal follow-up of 3 years ${ }^{33,34}$. After a median follow-up of 46 months, we observed that only $20 \%(5 / 25)$ of patients with UP had treatment success (the absence of colectomy during follow-up, no need for anti-TNF during follow-up, inactive disease at last follow-up, no ongoing systemic steroids at last follow-up and no AZA withdrawal due to adverse event) at last follow-up. Of note, even though AZA is a known to be a slow-acting drug, none of the non-primary responders exhibited clinical response in the long-term, indicating that biologics should be considered in case of lack of response after 9 months of AZA treatment in these patients. The long-term rate of mucosal healing in thiopurine-treated patients with UC is unknown. In this retrospective study, 18 out of 20 patients achieved mucosal healing in the long-term on AZA or IFX treatment. However, this rate of mucosal healing was observed after introduction of IFX treatment in 10 patients following AZA treatment failure. Hence, no definite conclusions can be drawn from our findings on mucosal healing rates among UC patients treated with AZA monotherapy.

Refractory patients with UC may ultimately require surgery. However, physicians are usually hesitating when considering colectomy in patients with refractory UP as there is no increased risk of colorectal cancer in these patients and as surgery is not a cure for $\mathrm{UC}^{35}$. A recent population based study found a $10 \%$ rate of surgery at 5 years among children with UP at diagnosis ${ }^{2}$. A similar rate of surgery was 
reported in our cohort of adult patients with refractory UP as 3 out of 25 patients required colectomy during the follow-up.

The safety profile observed in our cohort study with a high rate $(7 / 25,28 \%)$ of early AZA withdrawal related to drug intolerance is in line with previous reports ${ }^{25}$. No serious adverse event such as lymphoma or skin cancer was reported in our study, but it is clearly underpowered to address this issue.

Our study had several limitations. First, no predictors of response to AZA could be analyzed due to small sample size. Another limitation is the lack of control arm. However, the low rates of response to placebo in patients with severe or refractory UC, ranging in randomized controlled trials from 10 to $33 \%$ at short term and from $6.6 \%$ to $14 \%$ at long term ${ }^{36}$, may limit the risk of underestimating AZA effectiveness. Our study also has several strengths. Efficacy of thiopurine in treating UP was unknown and treating these patients is a challenge in clinical practice. As previously mentioned, patients with refractory UP are rarely treated with AZA. We could include 25 patients by reviewing databases of 3 French referral centers with a high volume of IBD patients and we had to screen over 1000 adult patients with UC. Furthermore, despite its retrospective study design, we could assess mucosal healing in the majority of patients in the long term (n=20). Finally, we used a hard composite endpoint to define treatment success (the absence of colectomy during follow-up, no need for anti-TNF during follow-up, inactive disease at last follow-up, no ongoing systemic steroids at last follow-up and no AZA withdrawal due to adverse event).

In conclusion, this multicenter retrospective study showed that AZA may be effective in one fifth of patients with refractory UP in a real-life setting. Our findings are clinically relevant as it is unlikely that a controlled trial will be ever conducted to assess the efficacy of thiopurine in refractory UP and as this is the first study specifically addressing this issue.

\section{Disclosures:}

Anne-Laure Mallet, Guillaume Conroy and Jean-Bernard Delobel declare having nothing to disclose. Guillaume Bouguen has received consulting fees from MSD and Abbvie and lecture fees from MSD, Abbvie, Takeda, Ferring. Laurent Siproudhis and Jean-Francois Bretagne have received lecture fees from Abbvie. Laurent Peyrin-Biroulet : Honoraria from Merck, Abbvie, Janssen, Genentech, Mitsubishi, Ferring, Norgine, Tillots, Vifor, Hospira/Pfizer, Celltrion, Takeda, Biogaran, Boerhinger-Ingelheim, Lilly, HAC-Pharma, Index Pharmaceuticals, Amgen, Sandoz, Forward Pharma GmbH, Celgene, Biogen, 
Lycera, Samsung Bioepis. Xavier Roblin received consulting fees from MSD, Abbvie,Takeda, Janssen, HAC Pharma

\section{Specific author contribution:}

GB, LPB: concept and design of the study, acquisition of data, analysis and interpretation of data, drafting the article, and language correction. ALM: acquisition of data analysis and drafting the article GC, JBD, LS and JFB: acquisition of data. All authors revised the article critically for important intellectual content and approved the version submitted including the author list.

\section{Acknowledgment: none}

\section{REFERENCES}

1. Meucci G, Vecchi M, Astegiano M, et al. The natural history of ulcerative proctitis: a multicenter, retrospective study. Gruppo di Studio per le Malattie Infiammatorie Intestinali (GSMII). Am J Gastroenterol 2000;95:469-73.

2. Hochart A, Gower-Rousseau C, Sarter H, et al. Ulcerative proctitis is a frequent location of paediatric-onset UC and not a minor disease: a population-based study. Gut 2016.

3. Moum B, Vatn MH, Ekbom A, et al. Incidence of ulcerative colitis and indeterminate colitis in four counties of southeastern Norway, 1990-93. A prospective population-based study. The Inflammatory Bowel South-Eastern Norway (IBSEN) Study Group of Gastroenterologists. Scand J Gastroenterol 1996;31:362-6.

4. Pagenault M, Tron I, Alexandre JL, et al. [Incidence of inflammatory bowel diseases in Bretagne (1994-1995). ABERMAD. Association Bertonne d'Etude et de Recherche des Maladies de l'Appareil Digesif]. Gastroenterol Clin Biol 1997;21:483-90.

5. Solberg IC, Lygren I, Jahnsen J, et al. Clinical course during the first 10 years of ulcerative colitis: results from a population-based inception cohort (IBSEN Study). Scand J Gastroenterol 2009;44:431-40.

6. Ayres RC, Gillen CD, Walmsley RS, et al. Progression of ulcerative proctosigmoiditis: incidence and factors influencing progression. Eur J Gastroenterol Hepatol 1996;8:555-8.

7. Bjornsson S, Johannsson JH, Oddsson E. Inflammatory bowel disease in Iceland, 1980-89. A retrospective nationwide epidemiologic study. Scand J Gastroenterol 1998;33:71-7.

8. Kruis W, Brandes JW, Schreiber S, et al. Olsalazine versus mesalazine in the treatment of mild to moderate ulcerative colitis. Aliment Pharmacol Ther 1998;12:707-15. 
9. Jess T, Riis L, Vind I, et al. Changes in clinical characteristics, course, and prognosis of inflammatory bowel disease during the last 5 decades: a population-based study from Copenhagen, Denmark. Inflamm Bowel Dis 2007;13:481-9.

10. Regueiro M, Loftus EV, Jr., Steinhart AH, et al. Clinical guidelines for the medical management of left-sided ulcerative colitis and ulcerative proctitis: summary statement. Inflamm Bowel Dis 2006;12:972-8.

11. Bouguen G, Roblin X, Bourreille A, et al. Infliximab for refractory ulcerative proctitis. Aliment Pharmacol Ther 2010;31:1178-85.

12. Lawrance IC, Copeland TS. Rectal tacrolimus in the treatment of resistant ulcerative proctitis. Aliment Pharmacol Ther 2008;28:1214-20.

13. Navas-Lopez VM, Blasco-Alonso J, Giron Fernandez-Crehuet F, et al. Successful treatment for ulcerative proctitis with rectal tacrolimus in an 8-year-old girl with intolerance to mesalamine. Clin J Gastroenterol 2014;7:320-3.

14. van Dieren JM, van Bodegraven AA, Kuipers EJ, et al. Local application of tacrolimus in distal colitis: feasible and safe. Inflamm Bowel Dis 2009;15:193-8.

15. Chande N, Wang Y, MacDonald JK, et al. Methotrexate for induction of remission in ulcerative colitis. Cochrane Database Syst Rev 2014:CD006618.

16. Ogata H, Matsui T, Nakamura M, et al. A randomised dose finding study of oral tacrolimus (FK506) therapy in refractory ulcerative colitis. Gut 2006;55:1255-62.

17. Chapman RW, Selby WS, Jewell DP. Controlled trial of intravenous metronidazole as an adjunct to corticosteroids in severe ulcerative colitis. Gut 1986;27:1210-2.

18. Turunen UM, Farkkila MA, Hakala K, et al. Long-term treatment of ulcerative colitis with ciprofloxacin: a prospective, double-blind, placebo-controlled study. Gastroenterology 1998;115:1072-8.

19. Sandborn WJ, Tremaine WJ, Schroeder KW, et al. A placebo-controlled trial of cyclosporin enemas for midly to moderately active left-sided ulcerative colitis. Gastroenterology 1994;106:1429-35.

20. Bibiloni R, Fedorak RN, Tannock GW, et al. VSL\#3 probiotic-mixture induces remission in patients with active ulcerative colitis. Am J Gastroenterol 2005;100:1539-46.

21. Bjorck S, Dahlstrom A, Ahlman H. Topical treatment of ulcerative proctitis with lidocaine. Scand J Gastroenterol 1989;24:1061-72.

22. Bloom S, Kiilerich S, Lassen MR, et al. Low molecular weight heparin (tinzaparin) vs. placebo in the treatment of mild to moderately active ulcerative colitis. Aliment Pharmacol Ther 2004;19:871-8.

23. Furrie E, Macfarlane S, Kennedy A, et al. Synbiotic therapy (Bifidobacterium longum/Synergy 1) initiates resolution of inflammation in patients with active ulcerative colitis: a randomised controlled pilot trial. Gut 2005;54:242-9. 
24. Thomas GA, Rhodes J, Ragunath K, et al. Transdermal nicotine compared with oral prednisolone therapy for active ulcerative colitis. Eur J Gastroenterol Hepatol 1996;8:769-76.

25. Timmer A, Patton PH, Chande N, et al. Azathioprine and 6-mercaptopurine for maintenance of remission in ulcerative colitis. Cochrane Database Syst Rev 2016:CD000478.

26. Love M, Rubin P, Chapman M, et al. 6-mercaptopurine is effective in intractable proctosigmoiditis. Gastroenterology 1995;100:A832.

27. Satsangi J, Silverberg MS, Vermeire S, et al. The Montreal classification of inflammatory bowel disease: controversies, consensus, and implications. Gut 2006;55:749-53.

28. Peyrin-Biroulet L, Sandborn W, Sands BE, et al. Selecting Therapeutic Targets in Inflammatory Bowel Disease (STRIDE): Determining Therapeutic Goals for Treat-to-Target. Am J Gastroenterol 2015;110:1324-38.

29. Beaugerie L, Itzkowitz SH. Cancers complicating inflammatory bowel disease. N Engl J Med 2015;372:1441-52.

30. Stewenius J, Adnerhill I, Ekelund GR, et al. Risk of relapse in new cases of ulcerative colitis and indeterminate colitis. Dis Colon Rectum 1996;39:1019-25.

31. Panaccione R, Ghosh S, Middleton S, et al. Combination therapy with infliximab and azathioprine is superior to monotherapy with either agent in ulcerative colitis. Gastroenterology 2014;146:392400 e3.

32. Travis SP, Stange EF, Lemann M, et al. European evidence-based Consensus on the management of ulcerative colitis: Current management. J Crohns Colitis 2008;2:24-62.

33. Ardizzone S, Maconi G, Russo A, et al. Randomised controlled trial of azathioprine and 5aminosalicylic acid for treatment of steroid dependent ulcerative colitis. Gut 2006;55:47-53.

34. Chebli LA, Chaves LD, Pimentel FF, et al. Azathioprine maintains long-term steroid-free remission through 3 years in patients with steroid-dependent ulcerative colitis. Inflamm Bowel Dis 2010;16:613-9.

35. Peyrin-Biroulet L, Germain A, Patel AS, et al. Systematic review: outcomes and post-operative complications following colectomy for ulcerative colitis. Aliment Pharmacol Ther 2016.

36. Garud S, Brown A, Cheifetz A, et al. Meta-analysis of the placebo response in ulcerative colitis. Dig Dis Sci 2008;53:875-91.

\section{FIGURE LEGEND}

Figure 1: Flow chart (Abbreviation: AZA, azathioprine; AE, adverse event; 5ASA, 5-aminosalicylate; IFX, infliximab) 


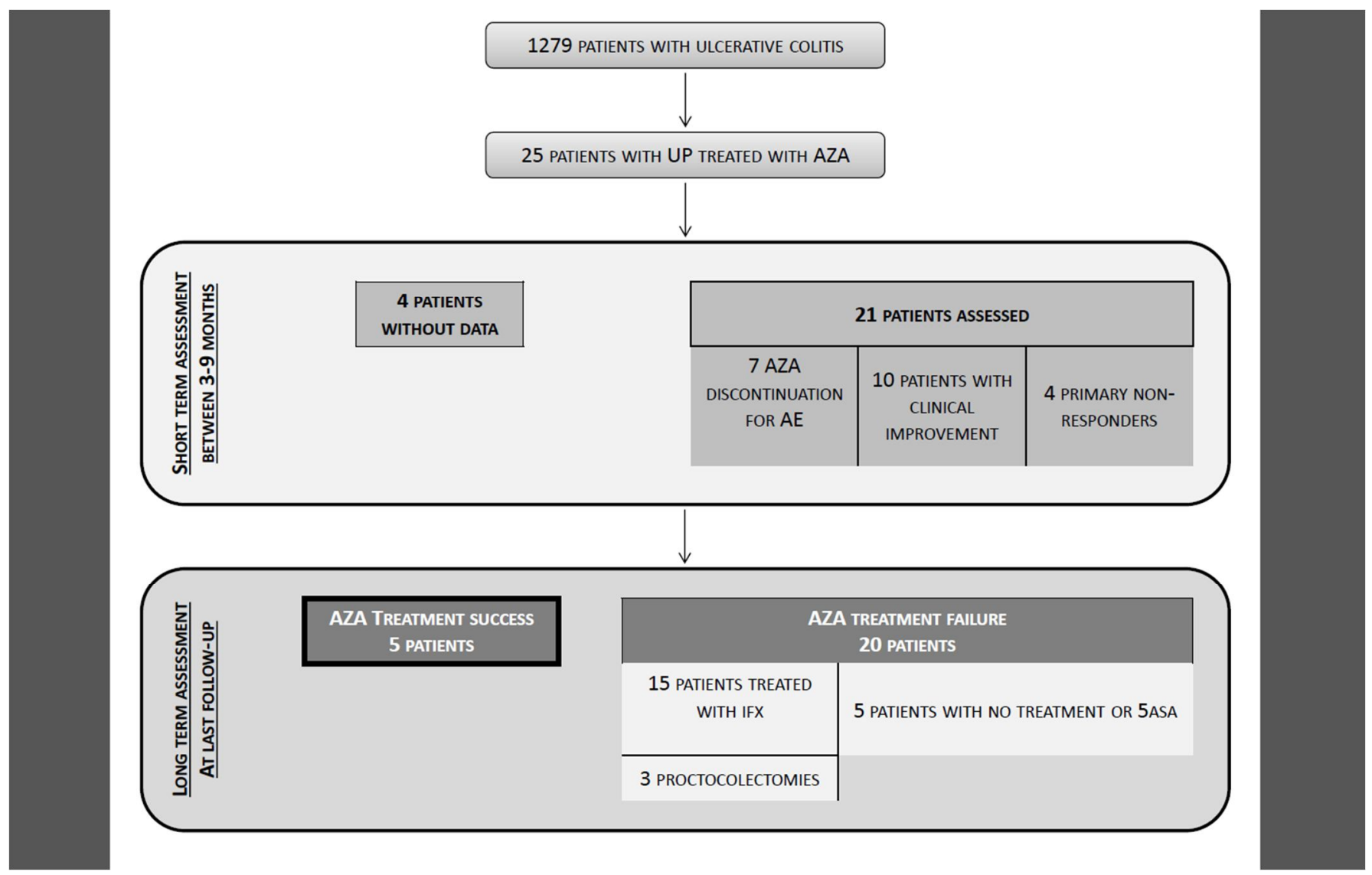

Table 1: Baseline characteristics of 25 patients with refractory ulcerative proctitis. The last seven patients discontinued AZA before 3 full months of treatment for adverse events. 


\begin{tabular}{|c|c|c|c|c|c|c|c|c|c|c|c|}
\hline \multirow{2}{*}{$\begin{array}{l}\text { Patient } \\
\text { No. }\end{array}$} & \multirow[b]{2}{*}{ SEX } & \multirow{2}{*}{$\begin{array}{c}\text { AGE (YR) } \\
\text { AT } \\
\text { DIAGNOSIS }\end{array}$} & \multirow{2}{*}{$\begin{array}{l}\text { DISEASE } \\
\text { DURATION } \\
\text { (months) }\end{array}$} & \multicolumn{2}{|c|}{$\begin{array}{c}\text { PREVIOUS } \\
\text { TREATMENT }\end{array}$} & \multirow{2}{*}{$\begin{array}{l}\text { CONCOMITANT } \\
\text { TREATMENT }\end{array}$} & \multirow{2}{*}{$\begin{array}{l}\text { NUMBER } \\
\text { OF } \\
\text { STOOLS/ } \\
\text { DAY }\end{array}$} & \multirow{2}{*}{$\begin{array}{l}\text { IMPORTANCE } \\
\text { OF RECTAL } \\
\text { BLEEDING* }\end{array}$} & \multirow{2}{*}{$\begin{array}{c}\text { RECTAL } \\
\text { DISORDER }\end{array}$} & \multirow{2}{*}{$\begin{array}{l}\text { CLINICAL } \\
\text { DISEASE } \\
\text { SEVERITY* }\end{array}$} & \multirow{2}{*}{$\begin{array}{c}\text { ENDOSCOPY } \\
* *\end{array}$} \\
\hline & & & & TOPICAL & ORAL & & & & & & \\
\hline 1 & M & 31 & 6 & ASA, CS & $\begin{array}{c}\text { ASA, } \\
\text { CS }\end{array}$ & $\mathrm{CS}$ & 1 & Mild & Absent & Mild & NA \\
\hline 2 & $\mathrm{~F}$ & 41 & 1 & ASA, CS & $\begin{array}{c}\text { ASA, } \\
\text { CS }\end{array}$ & $\mathrm{CS}$ & NA & Severe & Present & Severe & NA \\
\hline 3 & $\mathrm{~F}$ & 50 & 3 & $\mathrm{CS}$ & $\begin{array}{c}\text { ASA, } \\
\text { CS }\end{array}$ & ASA, CS & NA & Severe & Absent & Moderate & Severe \\
\hline 4 & $\mathrm{~F}$ & 20 & 4 & ASA, CS & $\begin{array}{c}\text { ASA, } \\
\text { CS }\end{array}$ & $\mathrm{CS}$ & NA & Severe & Present & Moderate & Mild \\
\hline 5 & $\mathrm{~F}$ & 11 & 1 & ASA, CS & $\begin{array}{c}\text { ASA, } \\
\text { CS }\end{array}$ & ASA & NA & Severe & Present & Moderate & Moderate \\
\hline 6 & $\mathrm{~F}$ & 23 & 15 & ASA, CS & $\begin{array}{c}\mathrm{ASA}, \\
\mathrm{CS}\end{array}$ & ASA, CS & NA & None & Absent & Moderate & NA \\
\hline 7 & $\mathrm{~F}$ & 33 & 14 & ASA, CS & $\begin{array}{c}\text { ASA, } \\
\text { CS }\end{array}$ & ASA, CS & 3 & Mild & Present & Moderate & Moderate \\
\hline 8 & M & 44 & 11 & ASA, CS & $\begin{array}{c}\mathrm{ASA} \\
\mathrm{CS}\end{array}$ & $\mathrm{CS}$ & 8 & Mild & Present & Moderate & NA \\
\hline 9 & $\mathrm{~F}$ & 72 & 2 & $\mathrm{CS}$ & $\begin{array}{c}\text { ASA, } \\
\text { CS }\end{array}$ & $\mathrm{CS}$ & NA & Mild & Present & Moderate & Moderate \\
\hline 10 & $\mathrm{~F}$ & 34 & 1 & ASA, CS & $\begin{array}{c}\mathrm{ASA}, \\
\mathrm{CS}\end{array}$ & $\mathrm{CS}$ & 4 & Severe & Present & Moderate & Moderate \\
\hline 11 & M & 36 & 21 & ASA, CS & $\begin{array}{l}\text { ASA, } \\
\text { CS, } \\
\text { Cyclo } \\
\end{array}$ & $\mathrm{CS}$ & 6 & Mild & Present & Severe & Severe \\
\hline 12 & $\mathrm{~F}$ & 31 & 5 & ASA, CS & $\begin{array}{c}\text { ASA, } \\
\text { CS }\end{array}$ & NA & 4 & Mild & Present & Moderate & Moderate \\
\hline 13 & $\mathrm{~F}$ & 51 & 5 & ASA, CS & $\begin{array}{c}\text { ASA, } \\
\text { CS }\end{array}$ & $\mathrm{CS}$ & 8 & Mild & Present & Severe & Severe \\
\hline 14 & M & 57 & 8 & ASA, CS & $\begin{array}{c}\text { ASA, } \\
\text { CS }\end{array}$ & ASA, CS & 8 & Mild & Present & Severe & Severe \\
\hline 15 & M & 45 & 4 & ASA & ASA & $\mathrm{ASA}, \mathrm{CS}$ & 8 & Mild & Present & Moderate & Moderate \\
\hline 16 & $\mathrm{~F}$ & 28 & 5 & ASA & ASA & ASA & 4 & Mild & Present & Moderate & Moderate \\
\hline 17 & M & 11 & 9 & ASA & ASA & ASA, CS & 3 & Mild & Present & Moderate & NA \\
\hline 18 & $\mathrm{~F}$ & 20 & 1 & ASA, CS & $\begin{array}{c}\text { ASA, } \\
\text { CS }\end{array}$ & ASA, CS & 4 & None & Present & Moderate & Moderate \\
\hline 19 & $\mathrm{~F}$ & 50 & 1 & ASA & $\begin{array}{c}\text { ASA, } \\
\text { CS }\end{array}$ & $\mathrm{CS}$ & NA & NA & NA & Moderate & Moderate \\
\hline 20 & $\mathrm{~F}$ & 27 & 2 & ASA & $\mathrm{CS}$ & ASA, CS & NA & NA & Absent & Mild & NA \\
\hline 21 & M & 47 & 8 & ASA & $\begin{array}{c}\text { ASA, } \\
\text { CS }\end{array}$ & $\mathrm{CS}$ & NA & NA & NA & Moderate & NA \\
\hline 22 & M & 40 & 21 & ASA & ASA & ASA & NA & Mild & Present & Moderate & Moderate \\
\hline 23 & M & 25 & 5 & ASA, CS & $\begin{array}{c}\text { ASA, } \\
\text { CS }\end{array}$ & ASA, CS & 6 & Mild & NA & Moderate & Moderate \\
\hline 24 & M & 35 & 10 & ASA, CS & $\begin{array}{c}\mathrm{ASA}, \\
\mathrm{CS}\end{array}$ & ASA, CS & 10 & Severe & Present & Severe & Moderate \\
\hline 25 & M & 57 & 3 & ASA, CS & $\begin{array}{c}\text { ASA, } \\
\text { CS }\end{array}$ & ASA & 6 & Mild & Present & Severe & Severe \\
\hline
\end{tabular}

Abbreviation: M, male; F, female; yr, years ; IFX, infliximab; ASA, aminosalicylate; CS, corticosteroid; Cyclo, cyclosporine; NA, not available.

*As judged by their physician.** Mayo's score. 